\title{
Comparison of Overall Survival after Nephron-Sparing Surgery and Radical Nephrectomy on the Basis of Preoperative Renal Function and Tumor Size
}

\author{
Tsuyoshi Yamaguchi ${ }^{1{ }^{\star}}$, Takatsugu Okegawa ${ }^{1}$, Eiji Higashihara $^{2}$ and Kikuo Nutahara ${ }^{1}$ \\ ${ }^{1}$ Department of Urology, Kyorin University School of Medicine, Tokyo, Japan \\ ${ }^{2}$ Department of ADPKD Research, Kyorin University School of Medicine, Tokyo, Japan \\ "Corresponding author: Tsuyoshi Yamaguchi, MD., Department of Urology, Kyorin University, School of Medicine, 6-20-2 Shinkawa, Mitaka, Tokyo 181-8611, Japan,
} Tel: +81422475511; Fax: +81422428431; E-mail: gussan0815@yahoo.co.jp

Received date: September 5, 2016; Accepted date: September 9, 2016; Publication date: September 12, 2016

Copyright: (c) 2016 Yamaguchi T, et al. This is an open-access article distributed under the terms of the Creative Commons Attribution License; which permits unrestricted use; distribution; and reproduction in any medium; provided the original author and source are credited.

\begin{abstract}
Objective: To compare the overall survival (OS) between radical nephrectomy (RN) and nephron-sparing surgery (NSS) by preoperative estimated glomerular filtration rate (eGFR) and tumor size.

Methods: Patients with cT1 renal tumors (NOM0) treated by RN or NSS between 1994 and 2014 were included. OS was compared by the surgical technique using Kaplan- Meier curves for the whole population. Then, subgroup analyses for OS were performed by the presence $\left(<60 \mathrm{ml} / \mathrm{min} / 1.73 \mathrm{~m}^{2}\right)$ or absence $\left(\geq 60 \mathrm{ml} / \mathrm{min} / 1.73 \mathrm{~m}^{2}\right)$ of preoperative chronic kidney disease (CKD) and by $\mathrm{cT} 1 \mathrm{a}$ and $\mathrm{cT} 1 \mathrm{~b}$ disease status. Multivariate analysis was also performed.
\end{abstract}

Results: 440 patients were included. There was no significant difference in OS by the surgical technique, including in patients with CKD. However, the group without CKD had a significantly better OS than the group with CKD. Moreover, compared with RN, the use of NSS was associated with a significantly better OS for patients without CKD, including those with CT1a tumors. There were no significant differences when OS was compared by the surgical technique in patients with CKD or CT1b tumors. Multivariate analysis showed that preoperative eGFR and tumor size were independent risk factors in the total population and the group without CKD, respectively.

Conclusion: We have shown that NSS can be beneficial for patients with preoperative non-CKD and stage cT1a tumors. RN and NSS produce comparable OS in patients with unfavorable preoperative renal function or tumor size. Further investigation is needed with larger populations.

Keywords: Chronic kidney disease; Nephron-sparing surgery; Overall survival; Preoperative renal function; Radical nephrectomy; Renal cell carcinoma; Tumor size

\section{Introduction}

Nephron-sparing surgery (NSS) is considered preferable to radical nephrectomy $(\mathrm{RN})$ for small renal tumors. NSS offers the same oncological benefits as $\mathrm{RN}$, including low onset of postoperative chronic kidney disease (CKD), good overall survival (OS), and few cardiovascular events [1-11].

Interestingly, Thompson et al. reported that NSS offered superior OS than RN in patients with T1a tumors [2]; however, there was no significant difference between NSS and RN in those with T1b tumors [6]. However, the only prospective, randomized comparative trial (EORTC 30904) has indicated that although NSS offered better postoperative renal function, the 10 year OS rate was significantly improved after RN $[12,13]$. The reasons for the results of the EORTC study are discussed in a study by Lane et al. [14]. They investigated whether CKD, which developed before or after kidney surgery, affected survival and reported that no correlation existed between the postoperative estimated glomerular filtration rate (eGFR) and OS in patients with a preoperative $e G F R \geq 60 \mathrm{ml} / \mathrm{min} / 1.73 \mathrm{~m}^{2}$.
To date, there has been no direct comparison of OS between RN and NSS considering the role of preoperative eGFR and tumor size using Kaplan- Meier curve analyses. Therefore, we studied patients with cT1a and cT1b tumors, with and without preoperative CKD, to compare OS following RN and NSS according to preoperative eGFR and tumor size.

\section{Materials and Methods}

\section{Patients}

Patients with cT1a or T1b (all N0M0) malignant renal tumors who underwent RN or NSS between 1994 and 2014 at Kyorin University Hospital were included. Patients observed for fewer than 6 months and those with missing data were excluded. Selection of NSS or RN was determined based on tumor size, position within the kidney, and patient status. Either open or laparoscopic surgery was performed.

\section{Procedures}

eGFR values were categorized relative to surgery as preoperative (most recent eGFR before surgery), postoperative (eGFR obtained after surgery). 
Citation: Yamaguchi T, Okegawa T, Higashihara E, Nutahara K (2016) Comparison of Overall Survival after Nephron-Sparing Surgery and Radical Nephrectomy on the Basis of Preoperative Renal Function and Tumor Size. J Nephrol Ther 6: 258. doi: 10.4172/2161-0959.1000258

Page 2 of 5

Our analysis was based on the methods used by Lane [14]. First, OS was compared on the basis of the surgical technique in the parent population. Next, the sample population was divided into two groups to compare OS on the basis of preoperative eGFR as follows: a group with a preoperative eGFR $\geq 60 \mathrm{ml} / \mathrm{min} / 1.73 \mathrm{~m}^{2}$ (i.e., the non-CKD group) and a group with a preoperative eGFR $<60 \mathrm{ml} / \mathrm{min} / 1.73 \mathrm{~m}^{2}$ (i.e., the CKD group). OS was also compared on the basis of the surgical technique in both the CKD and non-CKD groups, and then the CKD and non-CKD groups were divided into cTla and cT1b groups for further comparison.

Multivariate Cox proportional hazards regression analysis was performed on the total sample population and on the CKD and nonCKD groups. Preoperative eGFR was calculated using the abbreviated equation from the Cleveland Clinic Laboratory for the Modification of Diet in Renal Disease Study [15]: eGFR $=186 \times$ sCr-1.154 $\times$ age -0.203 ( $\times 0.742$ if female). Tumor size was defined as the maximum tumor diameter according to preoperative images. The characteristics of renal tumors were quantified using the RENAL nephrometry score [16]. The comorbidities were measured by the Charlson index [17].

\section{Statistical analysis}

For comparisons between RN and NSS, continuous variables were examined using the Mann-Whitney $U$ test, and categorical variables were examined using the chi-square test. OS was analyzed using Kaplan- Meier curves and compared with the log-rank test. Cox proportional hazards regression analyses were performed to investigate independent risk factors for OS. All statistical analyses were conducted using SAS version 9.4 (SAS Institute Inc., Cary, NC, USA), and a pvalue $<0.05$ was considered statistically significant.

\section{Results}

\section{Participants}

The clinical characteristics of the 440 participants are shown in Table 1. Among these, RN and NSS were performed on 289 and 151 patients, respectively. Compared with the NSS group, the age of the RN group was slightly higher $(\mathrm{p}=0.02)$. Although there was a male preponderance in both groups, there was no significant between-group difference. There were also non-significant, minor differences in the median body mass index and mean Charlson comorbidity index as well as in the proportions of patients with hypertension, diabetes mellitus, and non-clear cell cancer. However, there were significant differences in the median preoperative eGFR, median tumor size, and median RENAL nephrometry score.

\begin{tabular}{|c|c|c|c|}
\hline \multirow[t]{2}{*}{ Feature } & $\mathrm{RN}(\mathrm{n}=\mathbf{2 8 9})$ & NSS $(n=151)$ & $p$ value \\
\hline & \multicolumn{2}{|l|}{ Mean (median; range) } & \\
\hline Age at surgery, years & $63.3(65 ; 26-86)$ & $60.4(60 ; 33-86)$ & 0.02 \\
\hline Body mass index, $\mathrm{kg} / \mathrm{m} 2$ & $23.1(22.3 ;$ 13.6- 38.9) & $23.3(22.9 ; 17.6-32.5)$ & 0.2 \\
\hline Charlson comorbidity index & $0.63(0 ; 0-1)$ & $0.52(0 ; 0-1)$ & 0.18 \\
\hline Preoperative eGFR, $\mathrm{ml} / \mathrm{min} / 1.73 \mathrm{~m} 2$ & $70.6(68.2 ; 45.2-121.4)$ & $78.8(76.5 ; 49.1-120.9)$ & $<0.001$ \\
\hline Clinical tumor, $\mathrm{cm}$ & $4.6(4.0 ; 1.2-7.0)$ & $3.0(2.8 ; 1.0-7.0)$ & $<0.001$ \\
\hline RENAL nephrometry score & $8.25(9 ; 4-11)$ & $6.55(6 ; 4-11)$ & $<0.001$ \\
\hline Gender (\%) & & & 0.72 \\
\hline Male & 70.3 & 72 & \\
\hline Female & 29.7 & 28 & \\
\hline Hypertension (\%) & 44.4 & 40.3 & 0.41 \\
\hline Diabetes mellitus (\%) & 14.6 & 16.6 & 0.22 \\
\hline Non-clear cell type (\%) & 13.5 & 11.3 & 0.3 \\
\hline \multicolumn{4}{|l|}{ Operation (\%) } \\
\hline Open & 87.3 & 54.6 & $<0.001$ \\
\hline Laparoscopic & 12.7 & 45.4 & $<0.001$ \\
\hline
\end{tabular}

Table 1: Patient characteristics based on the type of surgery. eGFR: Estimated glomerular filtration rate, RN: Radical nephrectomy, NSS: Nephronsparing surgery. 
Citation: Yamaguchi T, Okegawa T, Higashihara E, Nutahara K (2016) Comparison of Overall Survival after Nephron-Sparing Surgery and Radical Nephrectomy on the Basis of Preoperative Renal Function and Tumor Size. J Nephrol Ther 6: 258. doi: 10.4172/2161-0959.1000258

Page 3 of 5

A

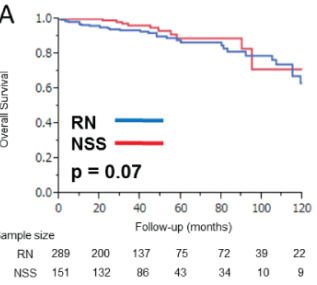

C 1.0

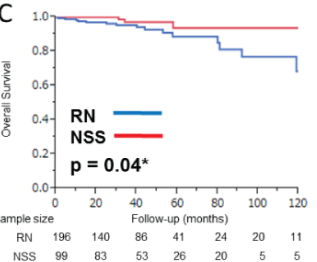

E

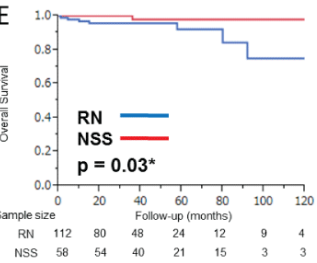

G

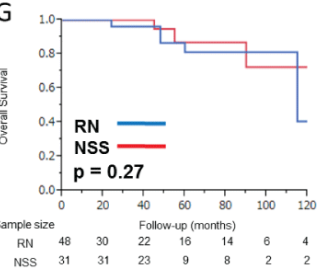

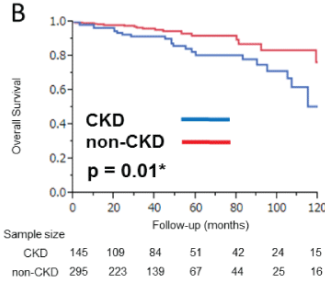

D 1
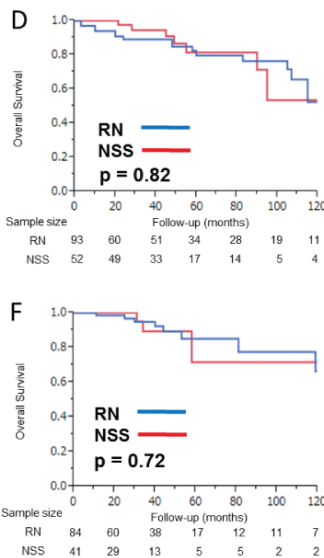

$\mathrm{H}$

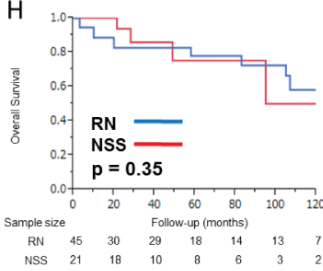

Figure 1: Kaplan- Meier curves comparing RN with NSS and CKD with non-CKD based on preoperative eGFR and tumor size. A: OS in the total population (RN and NSS). B: OS in the total population (CKD and non-CKD). C: OS in the non-CKD (RN and NSS). D: OS in the CKD (RN and NSS). E: OS in the non-CKD and cT1a (RN and NSS). F: OS in the non-CKD and cTlb (RN and NSS). G: OS in the CKD and cT1a (RN and NSS). H: OS in the CKD and cT1b (RN and NSS). CKD, a group with a preoperative eGFR of $<60 \mathrm{ml} / \mathrm{min} /$ $1.73 \mathrm{~m}^{2}$; non-CKD, a group with a preoperative eGFR of $\geq 60$ $\mathrm{ml} / \mathrm{min} / 1.73 \mathrm{~m}^{2}$; eGFR, estimated glomerular filtration rate; NSS, nephron-sparing surgery; RN, radical nephrectomy; OS, overall survival.

\section{Comparison of RN and NSS overall and by subgroup}

When the RN and NSS groups were compared in the total population, there was no significant difference in OS between the groups $(p=0.07$, Figure $1 \mathrm{~A})$. However, when that population was then divided into non-CKD and CKD groups, OS was significantly better in the non-CKD group ( $\mathrm{p}=0.01$, Figure $1 \mathrm{~B})$. Comparing OS according to the surgical technique in each group, OS was significantly better for NSS than for RN in the non-CKD group ( $\mathrm{p}=0.04$, Figure $1 \mathrm{C}$ ), but there was no significant difference between RN and NSS in the CKD group $(\mathrm{p}=0.82$, Figure $1 \mathrm{D})$.

Further analysis by dividing the non-CKD group into cT1a and cT1b groups indicated that OS was significantly better for NSS than for

$\mathrm{RN}$ in the cTla group ( $\mathrm{p}=0.03$, Figure $1 \mathrm{E})$ but that there was no significant difference between RN and NSS in the $\mathrm{cT} 1 \mathrm{~b}$ group $(\mathrm{p}=$ 0.72 , Figure $1 \mathrm{~F}$ ). A similar investigation was then performed in the CKD group, but no significant difference was found in terms of OS according to the surgical technique between the $\mathrm{CT} 1 \mathrm{a}$ and $\mathrm{cT} 1 \mathrm{~b}$ groups $(\mathrm{p}=0.27, \mathrm{p}=0.35$; Figures $1 \mathrm{G}, 1 \mathrm{H})$.

In the total population there were significant differences in the median preoperative eGFR and tumor size (Table 1). However OS was compared between RN and NSS with using stratified preoperative eGFR and tumor size. Therefore in each subgroup there was nosignificant difference in the preoperative eGFR and tumor size between RN and NSS (data not shown).

\section{Multivariate analysis}

The results of multivariate Cox proportional hazards regression analysis showed that preoperative eGFR $(\mathrm{p}=0.03)$ and tumor size $(\mathrm{p}<$ 0.001 ) were independent risk factors in the total population and nonCKD groups, respectively. There were no significant factors in the CKD group (Table 2).

\begin{tabular}{|c|c|c|c|c|c|c|}
\hline & \multicolumn{2}{|l|}{ All Pts } & \multicolumn{2}{|l|}{ CKD } & \multicolumn{2}{|c|}{ non-CKD } \\
\hline & $\begin{array}{l}\text { HR }(95 \% \\
\mathrm{Cl})\end{array}$ & p value & $\begin{array}{l}\text { HR } \\
(95 \% \\
\mathrm{Cl})\end{array}$ & $p$ value & $\begin{array}{l}\text { HR } \\
(95 \% \\
\mathrm{Cl})\end{array}$ & $p$ value \\
\hline Age & $\begin{array}{l}1.05 \\
(0.98-1.1 \\
2)\end{array}$ & 0.1542 & $\begin{array}{l}0.96 \\
(0.78-1 . \\
21)\end{array}$ & 0.6978 & $\begin{array}{l}1.15 \\
(1.00-1 \\
40)\end{array}$ & 0.0147 \\
\hline Gender & $\begin{array}{l}0.46 \\
(0.09-3.3 \\
9)\end{array}$ & 0.3972 & - & 0.6124 & $\begin{array}{l}0.35 \\
(0.02-4 . \\
65)\end{array}$ & 0.3143 \\
\hline $\begin{array}{l}\text { Body mass } \\
\text { index }\end{array}$ & $\begin{array}{l}0.92 \\
(0.76-1.1 \\
1)\end{array}$ & 0.4135 & $\begin{array}{l}1.01 \\
(0.69-1 . \\
47)\end{array}$ & 0.9216 & $\begin{array}{l}0.72 \\
(0.41-1 . \\
16)\end{array}$ & 0.0715 \\
\hline $\begin{array}{l}\text { Charlson } \\
\text { comorbidity } \\
\text { index }\end{array}$ & $\begin{array}{l}0.32 \\
(0.09-0.8 \\
3)\end{array}$ & 0.0179 & $\begin{array}{l}3.03 \\
(0.18-1 \\
22.9)\end{array}$ & 0.7227 & - & 0.0572 \\
\hline $\begin{array}{l}\text { Preoperative } \\
\text { eGFR }\end{array}$ & $\begin{array}{l}0.94 \\
(0.88- \\
0.99)\end{array}$ & 0.0306 & $\begin{array}{l}0.69 \\
(0.42-1 . \\
00)\end{array}$ & 0.061 & $\begin{array}{l}0.90 \\
(0.77-0 . \\
99)\end{array}$ & 0.0214 \\
\hline $\begin{array}{l}\text { Clinical tumor } \\
\text { size }\end{array}$ & $\begin{array}{l}1.01 \\
(0.99-1.0 \\
2)\end{array}$ & 0.4944 & $\begin{array}{l}1.01 \\
(0.97-1 . \\
04)\end{array}$ & 0.5255 & $\begin{array}{l}1.16 \\
(1.07-1 . \\
34)\end{array}$ & 0.0001 \\
\hline $\begin{array}{l}\text { Nephrectomy } \\
\text { (vs. NSS) }\end{array}$ & $\begin{array}{l}1.02 \\
(0.28-4.2 \\
4)\end{array}$ & 0.9777 & $\begin{array}{l}0.24 \\
(0.35-0 . \\
01)\end{array}$ & 0.3507 & $\begin{array}{l}0.50 \\
(0.02-15 \\
.10)\end{array}$ & 0.7497 \\
\hline
\end{tabular}

Table 2: Multivariate Cox regression analysis of risk factors for overall survival. CI: Confidence interval, CKD: a group with a preoperative eGFR of $<60 \mathrm{ml} / \mathrm{min} / 1.73 \mathrm{~m}^{2}$, non-CKD: a group with a preoperative eGFR of $\geq 60 \mathrm{ml} / \mathrm{min} / 1.73 \mathrm{~m}^{2}$, eGFR: estimated glomerular filtration rate, HR: Hazard ratio, RN: Radical nephrectomy, NSS: Nephronsparing surgery.

\section{Discussion}

In the present study, OS was compared according to the surgical technique, preoperative eGFR and tumor size in patients with cTla 
Citation: Yamaguchi T, Okegawa T, Higashihara E, Nutahara K (2016) Comparison of Overall Survival after Nephron-Sparing Surgery and

Radical Nephrectomy on the Basis of Preoperative Renal Function and Tumor Size. J Nephrol Ther 6: 258. doi: 10.4172/2161-0959.1000258

Page 4 of 5

and cT1b renal cell carcinoma (cT1N0M0). Our major results are summarized in Table 3. We report that NSS was associated with better OS in the non-CKD group with cT1a tumors and that there were no significant differences in OS according to the surgical technique between the non-CKD group with cT1b tumors and the CKD group.

\begin{tabular}{|c|c|c|c|}
\hline \multicolumn{4}{|l|}{ cT1N0M0 RCC patients } \\
\hline \multicolumn{4}{|l|}{ OS: no significant difference } \\
\hline \multicolumn{2}{|c|}{ preoperative eGFR $<60 \mathrm{ml} / \mathrm{min} / 1.75 \mathrm{~m}^{2}(\mathrm{CKD})$} & \multicolumn{2}{|c|}{ preoperative eGFR $<60 \mathrm{ml} / \mathrm{min} / 1.75 \mathrm{~m} 2$ (non-CKD) } \\
\hline \multicolumn{2}{|l|}{ OS: no significant difference } & \multicolumn{2}{|l|}{ OS: RN < NSS } \\
\hline Tumor size: cT1b & Tumor size: cT1a & Tumor size: cT1b & Tumor size: cT1a \\
\hline OS: no significant difference & OS: no significant difference & OS: no significant difference & OS: RN < NSS \\
\hline
\end{tabular}

Table 3: Summary of the main results. CKD: A group with a preoperative eGFR of $<60 \mathrm{ml} / \mathrm{min} / 1.73 \mathrm{~m}^{2}$; non-CKD: A group with a preoperative eGFR of $\geq 60 \mathrm{ml} / \mathrm{min} / 1.73 \mathrm{~m}^{2}$; eGFR: Estimated glomerular filtration rate; NSS: Nephron-sparing surgery; RN: Radical nephrectomy; OS: Overall survival.

In the total population there were significant differences in the median preoperative eGFR and tumor size (Table 1). However OS was compared between RN and NSS with using stratified preoperative eGFR and tumor size. Therefore in each subgroup there was nosignificant difference in the preoperative eGFR and tumor size between RN and NSS.

Most retrospective studies of the preferred surgical technique for obtaining the best OS have reported that RN is inferior to NSS [1-11]. Among these, Thompson et al. reported that in patients with Tla tumors, NSS offered superior OS than RN [2], whereas there was no significant difference between NSS and RN in patients with T1b tumors [6]. These studies also indicated that tumor size had a major influence on OS [2,6]. In comparison, the EORTC 30904 study indicated that $\mathrm{RN}$ was superior [12,13], showing postoperative 10 year OS rates of $81.1 \%$ and $75.5 \%$ for RN and NSS, respectively, with a relative risk of $1.59(\mathrm{p}=0.03)$. This was explained by Lane et al. [14]. who showed no correlation between postoperative renal function and OS in patients without medically induced CKD [Lane described with surgically induced CKD (CKD-S)]. However, Thompson [18] indicated that it remained questionable whether the results of the EORTC 30904 study $[12,13]$ could be applied to the CKD-S model because the EORTC study evaluated preoperative renal function with creatinine rather than eGFR, and they included creatinine scores that were higher than normal; moreover, although tumor size in the EORTC study was limited to $<5 \mathrm{~cm}$, some patients with T1b tumors would have been included in addition to those with T1a tumors. Furthermore, Lane et al. did not perform a direct comparison between OS for RN and NSS using Kaplan- Meyer curves, and they did not investigate the effect of tumor size. When comparing OS for RN and NSS, it is necessary to consider at least the preoperative eGFR and tumor size in the total population.

Our data support and build upon the previous research. No significant difference between RN and NSS was showed in the total population when it was not classified based on preoperative eGFR and tumor size $(p=0.07$, Figure $1 \mathrm{~A})$, which was consistent with the results of the EORTC 30904 report $[12,13]$. When the total population was then divided into non-CKD and CKD groups, the finding that OS was better in the non-CKD group ( $\mathrm{p}=0.01$, Figure $1 \mathrm{~B}$ ) was consistent with the results of the Lane et al. study [14]. However, we also report the following new findings, in addition to those described in the previous research: OS was significantly better for NSS than for RN in the non-
CKD group $(\mathrm{p}=0.04$, Figure $1 \mathrm{C})$; there was no significant difference between RN and NSS in the CKD group ( $p=0.82$, Figure 1D); OS was significantly better for NSS than for RN in the non-CKD group with cT1a tumors $(p=0.03$, Figure $1 \mathrm{E})$; and, there were no significant differences between RN and NSS in the non-CKD group with cT1b tumors, the CKD group with cTla tumors, and the CKD group with cT1b tumors $(\mathrm{p}=0.72, \mathrm{p}=0.27, \mathrm{p}=0.35$; Figure $1 \mathrm{~F}, 1 \mathrm{G}, 1 \mathrm{H})$. Multivariate Cox proportional hazards regression analysis of OS in the non-CKD group was used to confirm that tumor size was the strongest independent risk factor $(\mathrm{p}<0.001$, Table 2$)$.

Thus, OS is expected to change with the distributions of preoperative eGFR and tumor size in the population. It is plausible that this may have influenced the various conflicting results seen in previous studies. Indeed, when compared with RN, NSS is expected to impose greater stress on the residual renal parenchyma (e.g., ischemia and sutures) and to have greater potential for causing hypertension and major injury to the vascular and collecting systems in the early postoperative period [19-22]. In addition, the pathological stage of the tumor increases as the tumor diameter increases, thereby lowering OS. When preoperative renal function is adequate and the tumor size is small, there is a large amount of postoperative renal reserve. Therefore, the remnant renal tissue may be able to compensate for the harmful effects that occur after NSS, and it may be that the full benefits of NSS are being achieved. Meanwhile, because there is little postoperative renal reserve in patients with poor preoperative renal function or large tumors, the harmful effects of NSS may not be able to be compensated for, which probably decreases OS.

This study has some limitations. Notably, it was a retrospective study conducted at a single facility and with a small patient population. However, compared with the study by Lane et al., which was based on the OS results in the EORTC, our investigation increased the number of variables considered. If our findings can be confirmed and expanded upon in a larger sample, preoperative criteria for RN and NSS that are associated with improved outcomes could be identified.

\section{Conclusion}

In the present study, OS was compared according to the surgical technique in patients with stage cT1N0M0 renal cell carcinoma using preoperative eGFR and tumor size for subgroup analyses. We showed that the benefits of NSS apply to patients with a preoperative eGFR $\geq$ 
Citation: Yamaguchi T, Okegawa T, Higashihara E, Nutahara K (2016) Comparison of Overall Survival after Nephron-Sparing Surgery and

Radical Nephrectomy on the Basis of Preoperative Renal Function and Tumor Size. J Nephrol Ther 6: 258. doi: 10.4172/2161-0959.1000258

Page 5 of 5

$60 \mathrm{ml} / \mathrm{min} / 1.73 \mathrm{~m}^{2}$ and stage cTla tumors, and that there was no difference in OS between RN and NSS in patients with an unfavorable preoperative renal function or tumor size. Further investigation in larger populations is needed in the future.

\section{Acknowledgements}

Tsuyoshi Yamaguchi had full access to all the data in the study and takes responsibility for the integrity of the data and the accuracy of the data analysis.

Study concept and design, analysis and interpretation of data, drafting of the manuscript, statistical analysis: Yamaguchi.

Critical revision of the manuscript for important intellectual content: Okegawa, Nutahara, Yamaguchi.

Supervision: Yamaguchi, Okegawa and Nutahara.

\section{References}

1. Huang WC, Levey AS, Serio AM, Snyder M, Vickers AJ, et al. (2006) Chronic kidney disease after nephrectomy in patients with renal cortical tumours: a retrospective cohort study. Lancet Oncol 7: 735-740.

2. Thompson RH, Boorjian SA, Lohse CM, Leibovich BC, Kwon ED, et al. (2008) Radical nephrectomy for pT1a renal masses may be associated with decreased overall survival compared with partial nephrectomy. J Urol 179: 468-473.

3. Touijer K, Jacqmin D, Kavoussi LR, Montorsi F, Patard JJ, et al. (2010) The expanding role of partial nephrectomy: a critical analysis of indications, results, and complications. Eur Urol 57: 214-222.

4. Huang WC, Elkin EB, Levey AS, Jang TL, Russo P. (2009) Partial nephrectomy versus radical nephrectomy in patients with small renal tumors-is there a difference in mortality and cardiovascular outcomes? J Urol 181: 55-61.

5. Campbell SC, Novick AC, Belldegrun A, Blute ML, Chow GK, et al. (2009) Guideline for management of the clinical T1 renal mass. J Urol 182: 1271-1279.

6. Thompson RH, Siddiqui S, Lohse CM, Leibovich BC, Russo P, et al (2009) Partial versus radical nephrectomy for 4 to $7 \mathrm{~cm}$ renal cortical tumors. J Urol 182: 2601-2606.

7. Ljungberg B, Cowan NC, Hanbury DC, Hora M, Kuczyk MA, et al. (2010) EAU guidelines on renal cell carcinoma: the 2010 update. Eur Urol 58: 398-406.

8. Yokoyama M, Fujii Y, Iimura Y, Saito K, Koga F, et al. (2011) Longitudinal change in renal function after radical nephrectomy in Japanese patients with renal cortical tumors. J Urol 185: 2066-2071.

9. Kates M, Badalato GM, Pitman M, McKiernan JM (2011) Increased risk of overall and cardiovascular mortality after radical nephrectomy for renal cell carcinoma $2 \mathrm{~cm}$ or less. J Urol 186: 1247-1253.
10. Sun M, Bianchi M, Hansen J, Trinh QD, Abdollah F, et al. (2012) Chronic kidney disease after nephrectomy in patients with small renal masses: a retrospective observational analysis. Eur Urol 62: 696-703.

11. Kim SP, Thompson RH, Boorjuan SA, Weight CJ, Han LC, et al. (2012) Comparative effectiveness for survival and renal function of partial and radical nephrectomy for localized renal tumours: a systematic review and meta-analysis. J Urol 188: 51-57.

12. Van Poppel H, Da Pozzo L, Albrecht W, Matveev V, Bono A, et al. (2011) A prospective, randomised EORTC intergroup phase 3 study comparing the oncologic outcome of elective nephron-sparing surgery and radical nephrectomy for low-stage renal cell carcinoma. Eur Urol 59: 543-552.

13. Scosyrev E, Messing EM, Sylvester R, Campbell S, Van Poppel H (2014) Renal function after nephron-sparing surgery versus radical nephrectomy: results from EORTC randomized trial 30904. Eur Urol 65: 372-377.

14. Lane BR, Campbell SC, Demirjian S, Fergany AF. (2013) Surgically induced chronic kidney disease may be associated with a lower risk of progression and mortality than medical chronic kidney disease. J Urol 189: 1649-1655.

15. Levey AS, Bosch JP, Lewis JB, Greene T, Rogers N, et al. (1999) A more accurate method to estimate glomerular filtration rate from serum creatinine: a new prediction equation. Ann Intern Med 130: 461-470.

16. Kutikov A, Uzzo RG (2009) The R.E.N.A.L. nephrometry score: a comprehensive standardized system for quantitating renal tumor size, location and depth. J Urol 182: 844-853.

17. Charlson ME, Pompei P, Ales KL, MacKenzie CR (1987) A new method of classifying prognostic comorbidity in longitudinal studies: development and validation. J Chronic Dis 40: 373-383.

18. Thompson RH (2014) Partial versus radical nephrectomy: the debate regarding renal function ends while the survival controversy continues. Eur Urol 65: 378-379.

19. Funahashi Y, Hattori R, Yamamoto T, Kamihira O, Kato K, et al. (2009) Ischemic renal damage after nephron-sparing surgery in patients with normal contralateral kidney. Eur Urol 55: 209-215.

20. Smyth A, Collins CS, Thorsteinsdottir B, Madsen BE, Oliveira GH, et al. (2012) Page kidney: etiology, renal function outcomes and risk for future hypertension. J Clin Hypertens (Greenwich) 14: 216-221.

21. Inoue M, Fujii Y, Yokoyama M, Saito K, Numao N, et al. (2015) Progression of hypertension after partial nephrectomy in patients with renal tumors: A preliminary report. Int J Urol 22: 797-798.

22. L'esperance JO, Marguet CG, Walters RC, Sung JC, Auge BK, et al. (2010) Do nonspecific deep corticomedullary sutures performed during partial nephrectomy adequately control major vascular and collecting system injury? BJU Int 105: 411-415. 